\title{
Punicic acid is an $\omega-5$ fatty acid capable of inhibiting breast cancer proliferation
}

\author{
MICHAEL E. GROSSMANN, NANCY K. MIZUNO, TODD SCHUSTER and MARGOT P. CLEARY
}

University of Minnesota, Hormel Institute, 801 16th Ave. NE, Austin, MN 55912-3679, USA

Received October 16, 2009; Accepted November 27, 2009

DOI: 10.3892/ijo_00000515

\begin{abstract}
Pomegranate extracts have been used as anticancer agents and they contain a large number of potentially bioactive substances. Punicic acid is an $\omega-5$ long chain polyunsaturated fatty acid found in Punica granatum (pomegranate) seed oil. A number of long chain fatty acids have been reported to have cancer preventive actions. Here we investigated the potential ability of punicic acid to affect growth of both an estrogen insensitive breast cancer cell line (MDA-MB-231) and an estrogen sensitive cell line developed from the MDA-MB-231 cells (MDA-ER $\alpha 7$ ). Proliferation was inhibited 92 and 96\% for MDA-MB-231 and MDA-ER $\alpha 7$ cells, respectively compared to untreated cells by $40 \mu \mathrm{M}$ punicic acid. Furthermore, punicic acid induced apoptosis in the MDA-MB-231 and MDA-ER $\alpha 7$ cells by 86 and $91 \%$, respectively compared to untreated control cells and disrupted cellular mitochondrial membrane potential. We also investigated whether lipid oxidation was required for the function of punicic acid by adding $20 \mu \mathrm{M}$ of the antioxidant tocotrienol to the assays. This resulted in reversal of the effects of punicic acid on proliferation inhibition, apoptosis and disruption of the mitochondrial membrane potential. Finally, we evaluated the role of PKC signaling in the anti-cancer effects of punicic acid by performing proliferation assays in the presence of the PKC inhibitor bisindolymaleimide I. Proliferation inhibition by punicic acid was partially blocked in both the MDA-MB231 and MDA-ER $\alpha 7$ cells. These results suggest that punicic acid has breast cancer inhibitor properties that are dependent on lipid peroxidation and the PKC pathway.
\end{abstract}

\section{Introduction}

Pomegranate (punica granatum) is a well known alternative medicine and various extracts from pomegranate are utilized as supplements with a wide variety of purported health benefits including anticancer actions (1). These supplements contain a

Correspondence to: Dr Margot P. Cleary, University of Minnesota, Hormel Institute, 801 16th Ave. NE, Austin, MN 55912-3679, USA E-mail: mpcleary@smig.net

Key words: breast cancer, pomegranate, oxidation, apoptosis number of different components that under some conditions either activate or inhibit estrogen, lower oxidation of LDL cholesterol, reduce arterial plaques, lower oxidative stress, enhance wound healing, inhibit angiogenesis, inhibit tumor proliferation and increase tumor apoptosis (1-3). However, these studies have been conducted with fruit, seeds, pericarp or partially purified extracts making it hard to determine what the active component(s) of pomegranate may be.

Dietary fats may be capable of anticancer effects, particularly in the case of breast cancer. There are a number of different types of fatty acids including long chain polyunsaturated fatty acids (LC-PUFA) known to be capable of cancer inhibition. Conjugated linoleic acid (CLA) and the omega 3 ( $\omega$-3) LC-PUFAs, eicosapentaenoic acid (EPA) and docosahexaenoic acid (DHA) that are found in fish oil have been the most widely studied (4-6). However, a less examined group of rare omega $5(\omega-5)$ LC-PUFAs may have even greater cancer inhibition properties. Punicic acid (PA), also known as 9Z,11E,13Z-octadecatrienoic acid, is an $\omega-5$ LCPUFA that makes up approximately $65-80 \%$ of the oil from pomegranate seeds (7), it is structurally very similar to CLA and $\alpha$-linolenic acid (ALA) which have been found to have various health benefits $(8,9)$ including cancer prevention (9). A previous in vitro study suggested that pure punicic acid may be an anti-cancer constituent in pomegranate as evidenced by the fact that punicic acid was able to significantly reduce invasion of PC-3 cells using a Matrigel membrane assay (10). This finding, in combination with the structural similarities between PA and CLA led us to examine PA for inhibitory effects against breast cancer.

In this study we investigated the anticancer effects of purified PA as illustrated by proliferation and apoptosis using human breast cancer (brca) cells with and without estrogen receptor. We compared the effects of PA with CLA and ALA since they have been studied extensively for their potential anticancer activities. We also examined potential pathways and mechanisms of action by which PA may be functioning. Clarification of the actions of PA may lead to a better understanding of how PA specifically and dietary fats in general impact cancer cells.

\section{Materials and methods}

Cell culture. MDA-MB-231 cells were obtained from ATCC (Manassas, VA) and maintained in L-15 media (ATCC, Manassas, VA) with 10\% FCS (Atlanta Biologics, 
Lawrenceville, GA) and pen/strep (Gibco, Grand Island, NY). The MDA-ER $\alpha 7$ cell line (11) is a clone of the MDA-MB-231 cell line transfected with the ER $\alpha$ gene followed by selection with $200 \mu \mathrm{g} / \mathrm{ml}$ of zeocin (Promega, Madison, WI). The MDA-ER $\alpha 7$ cell line was maintained in the same media as the MDA-MB-231 cells except that $200 \mu \mathrm{g} / \mathrm{ml}$ zeocin was added to the media.

Growth assays. Cells were harvested, counted, plated at a density of $5 \times 10^{3}$ cells per well in 96 -well plates, and allowed to attach overnight in an incubator maintained at $37^{\circ} \mathrm{C}$ without additional $\mathrm{CO}_{2}$. The following day, complete medium was removed from the wells and treatment of the cells with PA in complete media was performed. The cells were then incubated for $48 \mathrm{~h}$, at which time a cell proliferation assay was performed using $10 \mu \mathrm{l}$ of CCK- 8 reagent from the Cell Counting kit- 8 as per manufacturer's instructions (Dojindo Laboratories, Japan). In this assay a formazan dye is generated by the activity of dehydrogenases in cells that is directly proportional to the number of living cells. The plates were then incubated for $1.5-3 \mathrm{~h}$ depending on the cell line in a $37^{\circ} \mathrm{C}$ incubator, after which the plates were read on an ELISA reader at $450 \mathrm{~nm}$. CLA and ALA were obtained from Sigma-Aldrich (St. Louis, MO) and PA was obtained from Larodan Fine Chemicals (Malmo, Sweden).

Analysis of cell cycle, apoptosis and mitochondrial transmembrane potential $(\Delta \Psi \mathrm{m})$. Cells were plated at $1 \times 10^{6}$ in $10 \mathrm{~cm}$ plates and allowed to adhere for $36 \mathrm{~h}$. Cells were then treated as described for each assay and $48 \mathrm{~h}$ later were analyzed for cell cycle, apoptosis or $\Delta \Psi \mathrm{m}$. For cell cycle analysis, cells were harvested with $0.025 \%$ trypsin $+5 \mathrm{mM}$ EDTA in PBS. After washing with PBS, the cells were resuspended in $0.4 \mathrm{ml}$ of PBS and $1 \mathrm{ml}$ of ice-cold absolute ethanol was added and mixed immediately. Cells were fixed at $-20^{\circ} \mathrm{C}$ for a minimum of $2 \mathrm{~h}$ and then washed with PBS. Cells were incubated with propidium iodide, $20 \mu \mathrm{g} / \mathrm{ml}$ and RNAase, $200 \mu \mathrm{g} / \mathrm{ml}$, for $30 \mathrm{~min}$ at room temperature in the dark. Cells were analyzed on a Becton-Dickinson FACSCalibur flow cytometer (BD Biosciences, San Jose, CA). Intact cells were gated in the FSC/SSC plot to exclude small debris. Cell cycle was determined using ModFit LT software (Verity Software House, Inc., Topsham, ME). Apoptosis was evaluated using the Annexin V-FITC Apoptosis Detection kit from MBL International Corporation, Watertown, MA. Cells were harvested with $0.025 \%$ trypsin $+5 \mathrm{mM}$ EDTA in PBS, and $2.5 \%$ FBS in PBS was added as soon as the cells were released from the dish. Then the cells were transferred to a centrifuge tube, washed with PBS and incubated for $5 \mathrm{~min}$ at room temperature with Annexin V-FITC plus propidium iodide (PI) following the protocol included in the kit. Cells were analyzed on a Becton-Dickinson FACSCalibur flow cytometer (BD Biosciences, San Jose, CA), placing the FITC signal in FL1 and the PI signal in FL2. Intact cells were gated in the FSC/SSC plot to exclude small debris. Cells in the lower right quadrant of the FL1/FL2 dot plot (labeled with Annexin V-FITC only) are considered to be in early apoptosis, and cells in the upper right quadrant (labeled with Annexin V-FITC and PI) are in late apoptosis/necrosis. Disruption of the mitochondrial membrane potential $(\Delta \Psi \mathrm{m})$ was analyzed with Mitocapture Apoptosis Detection kit (Biovision) used as per instructions. In apoptotic cells, MitoCapture dye does not accumulate in mitochondria but remains as monomers in the cytoplasm, and fluoresces green. The results were analyzed by FACS.

Statistics. All data analysis was performed using GraphPad Prism ${ }^{\circledR}$ version 4.0. Proliferation assays were performed 3-7 times using triplicate wells each time and are presented as means \pm SE. Two-way analysis of variance was utilized to compare the data from the proliferation assays and one-way analysis of variance was utilized for the remaining studies with significant differences defined as $\mathrm{P}<0.05$. If the oneway analysis of variance was significant then the NewmanKeuls post test was used to compare all pairs of columns. Significance between specific groups using Newman-Keuls was defined as $\mathrm{P}<0.05$.

\section{Results}

Ability of PA to inhibit brca growth and induce apoptosis. We tested whether PA inhibits proliferation of the MDA-ER $\alpha 7$ and MDA-wt cells in vitro. As shown in Fig. 1, PA was capable of inhibition of cell proliferation of both cell lines with only $4.5 \%$ proliferation for MDA-ER $\alpha 7$ and $8.5 \%$ proliferation for MDA-wt at $40 \mu \mathrm{M}$ of PA compared to untreated control cells for each cell line (100\%). On the other hand CLA and ALA, though very similar to PA structurally, had comparatively weak antiproliferative activity at $40 \mu \mathrm{M}$ with no significant differences in proliferation for CLA or ALA in the MDA-ER $\alpha 7$ or the MDA-wt cells as compared to untreated controls for each cell line. It has previously been reported that higher doses of CLA significantly reduced proliferation of MDA-MB-231 cells but that at lower doses such as we used there was negligible inhibition of proliferation (12). The presence of ER $\alpha$ did not noticeably impact the effect of PA, CLA or ALA on brca cell proliferation. Inhibition of proliferation does not necessarily equate with cell death which is our goal for treatment of mammary tumors so we examined apoptosis utilizing a FACS based annexin-V assay. PA treatment of brca cells resulted in high levels of apoptosis for both cell lines in the range of $86-91 \%$ at $40 \mu \mathrm{M}$ while CLA and ALA treatment at $40 \mu \mathrm{M}$ resulted in only $5-10 \%$ of cells in apoptosis which was not significantly different from results for untreated control cells. There were no significant differences in apoptosis between the MDA-ER $\alpha 7$ and MDA-wt cells when they were treated with PA, CLA, or ALA. These findings clearly illustrate that PA has very profound anti-mammary tumor effects in vitro.

Lipid peroxidation and $P A$. The potential for lipid peroxidation to play a role in the antiproliferative effect of PA on the brca cells was investigated. MDA-ER $\alpha 7$ and MDA-wt cells were treated with $\alpha$-tocotrienol, a form of vitamin $\mathrm{E}$ with antioxidant activity (13), $1 \mathrm{~h}$ prior to and during treatment with PA. We hypothesized that the use of an antioxidant should reduce lipid peroxidation and prevent inhibition of cell proliferation by PA. Fig. 2A shows that when the cells were treated with PA in the presence of $20 \mu \mathrm{M} \alpha$-tocotrienol inhibition by PA was lost with both the MDA-ER $\alpha 7$ and 
A.

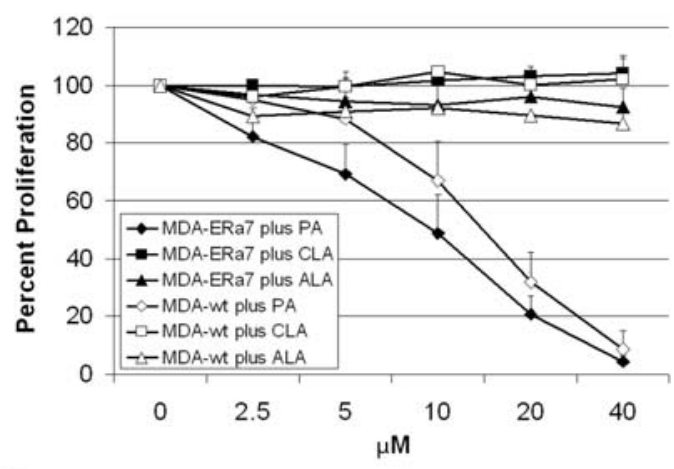

B.

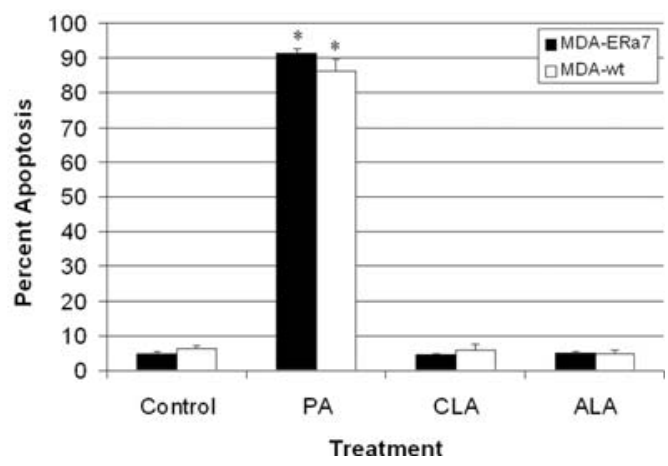

Figure 1. Proliferation and apoptosis of breast cancer cell lines in response to PA. (A) Two-way ANOVA $\mathrm{P}<0.0001$ for differences between the treatments. Cell proliferation as a percent is shown along the y-axis. Untreated cells given complete media instead of the treatments were considered to be $100 \%$. The concentrations of PA, CLA and ALA are shown along the x-axis. Bars represent standard error of the mean. Three to seven separate assays were performed with triplicate wells in each assay. (B) One-way ANOVA $\mathrm{P}<0.0001$ for the difference between the treatments as a whole. Apoptosis as a percent is shown on the $\mathrm{y}$-axis. The treatments are shown along the $\mathrm{x}$-axis. Cells were treated for $48 \mathrm{~h}$ using $40 \mu \mathrm{M}$ concentrations of PA, CLA or ALA. Untreated cells given complete media are the control. Bars represent standard error of the mean of 4 experiments. Asterisk show significant differences between specific concentrations of the treatments.

MDA-wt retaining $82 \%$ of their proliferation potential. In addition when we measured apoptosis in the presence of $20 \mu \mathrm{M}$ $\alpha$-tocotrienol the ability of PA to induce apoptosis was completely blocked (Fig. 2B).

Mitochondrial membrane potential and PA. To identify what parts of the apoptosis pathway are important for the effects of PA and to further examine the role of oxidation we determined whether the mitochondrial transmembrane potential $(\Delta \Psi \mathrm{m})$ was affected by PA treatment. Cells were incubated with $40 \mu \mathrm{M}$ PA for $48 \mathrm{~h}$ and then the $\Delta \Psi \mathrm{m}$ was determined using a Mitocapture Apoptosis Detection kit (Biovision). In apoptotic cells, MitoCapture dye does not accumulate in mitochondria rather it remains as monomers in the cytoplasm and fluoresces green. However, in healthy cells it accumulates in the mitochondria and fluoresces red. Here treatment with PA led to a significant difference from controls $(\mathrm{P}<0.001)$ with 91 and $86 \%$ of the treated MDA-ER $\alpha 7$ and MDA-wt cells, respectively, having disruption of the $\Delta \Psi \mathrm{m}$ (Fig. 3) compared to only 7.1 and $4.8 \%$ disruption of the $\Delta \Psi \mathrm{m}$ for the MDAER $\alpha 7$ and MDA-wt untreated controls, respectively. The addition of $\alpha$-tocotrienol blocked the effects of PA such that
A.

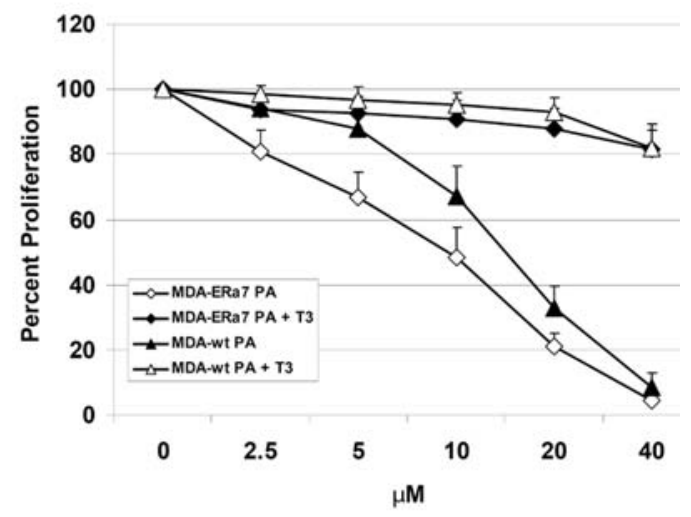

B.

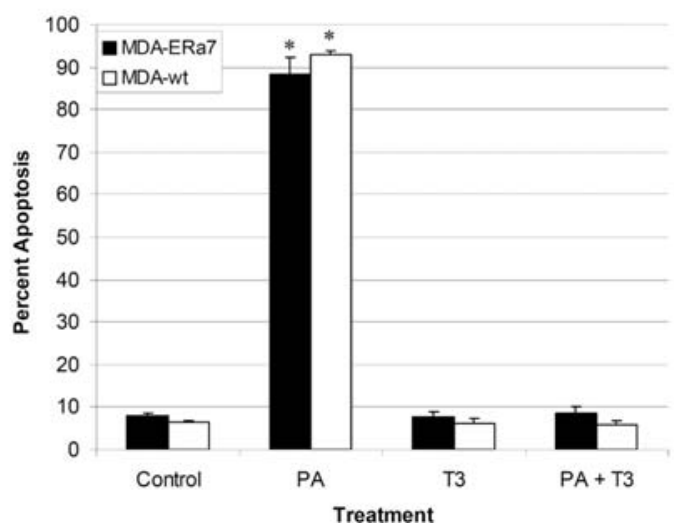

Figure 2. Effects of the antioxidant $\alpha$-tocotrienol on proliferation and apoptosis of breast cancer cells in response to PA. (A) Two-way ANOVA $\mathrm{P}<0.0001$ for differences between the treatments. Cell were plated, allowed to adhere overnight, treated with PA in the presence or absence of $20 \mu \mathrm{M}$ tocotrienol (T3) and $48 \mathrm{~h}$ later the proliferation assays were performed as described above. Cell proliferation as a percent is shown along the y-axis. Untreated cells given complete media instead of the treatments were considered to be $100 \%$. The concentration of PA is shown along the $\mathrm{x}$-axis. Bars represent standard error of the mean. Three separate experiments were performed with triplicate wells in each assay. (B) One-way ANOVA $\mathrm{P}<0.0001$ for the difference between the treatments as a whole. Apoptosis as a percent is shown on the $y$-axis. Untreated cells given complete media are the control. The treatments are shown along the $\mathrm{x}$-axis. The concentration of PA was $40 \mu \mathrm{M}$ and the concentration of Toc was $20 \mu \mathrm{M}$. Cells were treated for $48 \mathrm{~h}$. Bars represent standard error of the mean from 3 experiments. Asterisk show significant differences between specific concentrations of the treatments.

the $\Delta \Psi \mathrm{m}$ levels were not significantly different than that of the untreated control cells for each cell line. These results suggest that PA is activating apoptosis in part via the intrinsic pathway in an oxidation dependent manner in vitro.

Cell cycle blockage by PA. The ability of PA to cause alterations in the cell cycle was also investigated. Exposure to $40 \mu \mathrm{M}$ PA increased the percentage of cells in the $\mathrm{G} 2 / \mathrm{M}$ phase (Fig. 4). The percent of MDA-ER $\alpha 7$ cells in the G2/M phase increased from 27.3 to $41.3 \%$ and the percent of MDA-wt cells in the G2/M phase increased from 12.3 to $20.3 \%$ in the presence of $40 \mu \mathrm{M}$ PA for $48 \mathrm{~h}$. The percentage of cells in the G2/M phase under both untreated and treated conditions was different for the two cell lines but the increases in the $\mathrm{G} 2 / \mathrm{M}$ phase following PA treatment were similar for both lines. 


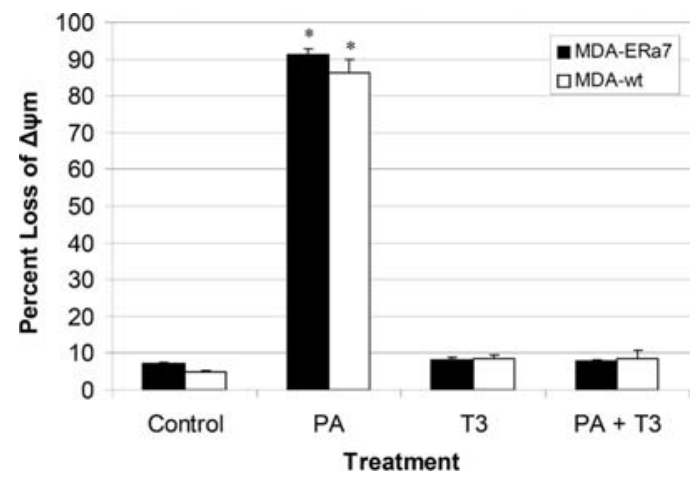

Figure 3. PA treatment effects on the mitochondrial membrane potential. One-way ANOVA $\mathrm{P}<0.0001$ for the difference between the treatments as a whole. Cells were treated with PA in the presence or absence of $20 \mu \mathrm{M}$ $\alpha$-tocotrienol (T3) for $48 \mathrm{~h}$. Cells with disruption of the mitochondrial membrane are shown on the y-axis in percent. The concentration of PA was $40 \mu \mathrm{M}$ and the concentration of $\mathrm{T} 3$ was $20 \mu \mathrm{M}$.

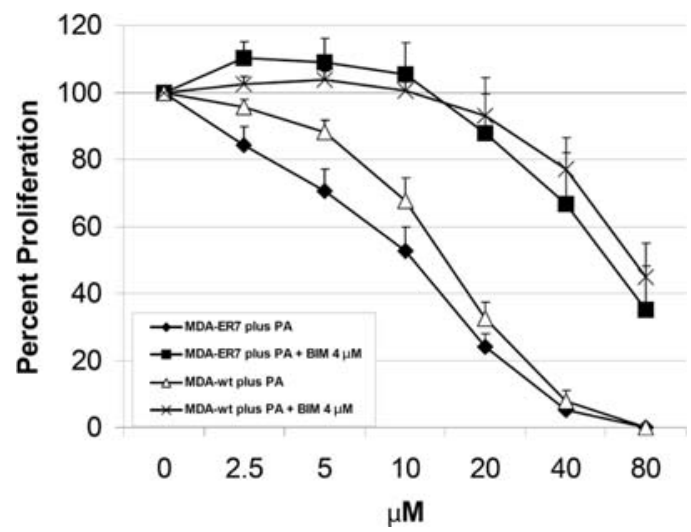

Figure 5. Response of breast cancer cells to PA with PKC inhibitor. Two-way ANOVA $\mathrm{P}<0.0001$ for differences between the treatments. Cells were plated, allowed to adhere overnight, pretreated with bisindolylmaleimide I (BIM) for $1 \mathrm{~h}$ and then treated with PA in $4 \mu \mathrm{M}$ BIM for $48 \mathrm{~h}$. The proliferation assays were performed using the Cell Counting kit- 8 as per manufacturer's instructions (Dojindo). Cell proliferation as a percent is shown along the $\mathrm{y}$-axis. Untreated cells given complete media instead of the treatments were considered to be $100 \%$. The concentration of PA is shown along the $\mathrm{x}$-axis. Bars represent standard error of the mean. Three separate experiments were performed with triplicate wells in each assay.

PKC activation and PA function. Protein kinase C (PKC) has been shown to be activated by diacylglycerol $(14,15)$ which can be synthesized using glycerol and PUFA. We found that the PKC inhibitor bisindolymaleimide I (BIM) partially blocked the antiproliferative effects of PA for both MDAER $\alpha 7$ and MDA-wt cells (Fig. 5). The blockage was significantly different from untreated controls in cells treated with 5-80 $\mu \mathrm{M}$ PA for the MDA-ER $\alpha 7$ cells. There was significant inhibition of the effects of PA on the MDA-wt at concentrations of 10-80 $\mu \mathrm{M}$. There was no significant difference between MDA-ER $\alpha 7$ and MDA-wt cells that had been treated with PA and BIM (upper two lines).

\section{Discussion}

We are the first to show direct inhibition of human brca cell proliferation by the $\omega-5$ LC-PUFA, punicic acid. A number

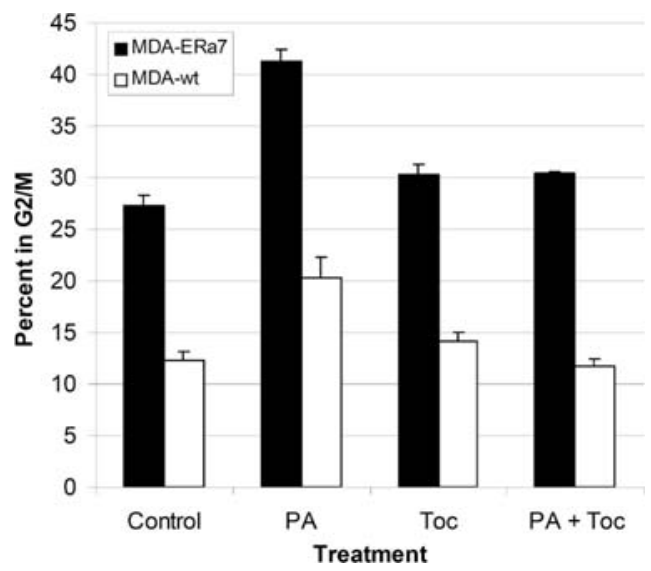

Figure 4. PA treatment results in a G2/M cell cycle block. One-way ANOVA $\mathrm{P}<0.0001$ for the difference between the treatments as a whole. Letters show significant differences between specific treatments. Cells in G2/M are shown as a percent along the $\mathrm{y}$-axis. Untreated cells given complete media instead of the treatments are the control. The treatments are shown along the $\mathrm{X}$-axis. Bars represent standard error of the mean from three experiments.

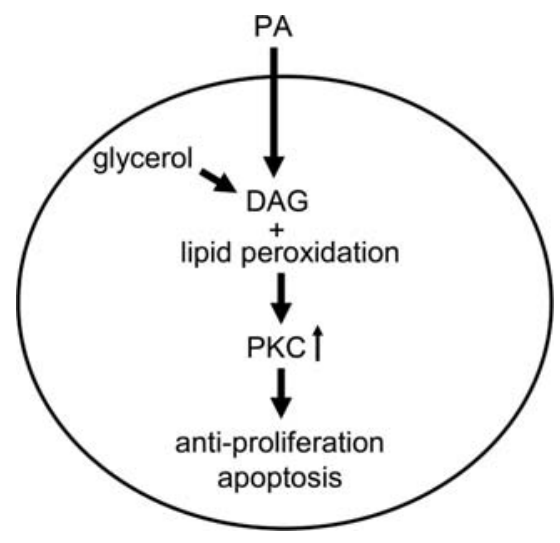

Figure 6. Potential pathway for punicic acid actions on breast cancer cells. PA, punicic acid; DAG, diacylglycerol and PKC, protein kinase C.

of studies have suggested that various pomegranate extracts have anticancer activity but no prior study has evaluated the specific effects of PA in relation to brca. Punicic acid was capable of dramatic anti-tumor properties in vitro with inhibition of proliferation in the range of $92-96 \%$. PA treatment not only halted cell proliferation it also induced apoptosis (86-91\%). Apoptosis induction may be related to the fact that there was significant $\Delta \Psi \mathrm{m}$ disruption. A possible mechanism of action, lipid peroxidation, was identified by the fact that the antioxidant tocotrienol was able to block the PA inhibitory and apoptotic actions on these brca cells. Finally, PKC signaling may also represent a portion of the pathway utilized by PA since inhibition of PKC signaling partially blocked the PA effects. A potential pathway is presented in Fig. 6. Punicic acid enters the cell and is utilized in synthesis of diacylglycerol (DAG). If lipid peroxidation has occurred, DAG will activate PKC which then leads to inhibition of proliferation and activation of apoptosis.

Lipid peroxidation is the oxidative destruction of polyunsaturated fatty acids through an autocatalytic free radical chain reaction and is associated with the loss of membrane 
fatty acids and the formation of hydroperoxides, free radical intermediates, and other secondary lipid peroxidation products such as aldehydes and related carbonyl compounds $(16,17)$. Oxidative stress arises during lipid peroxidation through the generation of lipid peroxidation products and other reactive oxygen species. While the process of lipid peroxidation and the formation of lipid peroxidation products have been associated with the pathogenesis of several human diseases including heart disease, diabetes, and cancer (18-22), it has been suggested that lipid peroxidation may have a possible role in the prevention of breast cancer (23-25). Some cancer cells are intrinsically more sensitive to oxidative stress than their normal counterparts (26-28). As a result, the presence of lipid peroxidation products or reactive oxygen species can trigger apoptosis through death-receptor signaling, downregulation of cell survival receptor-mediated signaling, and changes in membrane phospholipids composition (29-32). Furthermore, there is evidence that mouse mammary tumors are more sensitive than normal tissues to the induction of reactive oxygen species-mediated apoptosis (33) and that developing tumors in vivo are inherently susceptible to dietinduced increased oxidative stress resulting in decreased tumor growth and progression $(33,34)$. It has been proposed that the protective effect of dietary $\omega-3$ fatty acids against mammary tumor development may be due to the presence of lipid peroxidation products arising from the peroxidation of $\omega-3$ fatty acids (35). Therefore, reactive oxygen species may have dual roles whereby low levels result in normal protective signaling, intermediate levels lead to a variety of cellular damage promoting tumorigenesis and high levels could promote oxidative burst and cell death (reviewed in ref. 36).

PKC can be activated by DAG and has been suggested to be involved in a number of aspects of tumor progression but has not been found to be strongly correlated with any aspects of breast cancer progression (37). This may be in part due to the fact that there are several different PKC isozymes that phosphorylate a variety of target proteins which control antiproliferation and apoptosis as well as proliferation and survival (38). Diacylglycerol is actually an extremely varied molecule that can be composed of various glycerol compounds linked to two fatty acids which can also be highly varied resulting in many different compounds that are all known as DAG. The various DAG molecules can differentially activate the PKC isozymes (38) and it seems probable that this is in some way linked to the ability of PA to inhibit proliferation.

In summary, many studies indicate that the type of dietary fat may be pivotal for inhibition of brca. Here, we have characterized how PA, an $\omega$-5 LC-PUFA, impacts human brca cell lines in vitro. The present results using PA are in agreement with previous findings using a similar $\omega-5$ LCPUFA, eleostearic acid that makes up approximately $60 \%$ of Momordica charantia (bitter melon) seed oil and was shown to have similar antibrca effects that were also peroxidation dependent (39). Pomegranate extracts are more readily available than bitter melon seed oil, more palatable and more acceptable to individuals from Western societies. Hopefully the present study will be useful for defining preclinical studies and eventually in making dietary recommendations to women. The combination of known health benefits with an active market for dietary supplements has led to many claims of health benefits for pomegranate extract but few scientifically proven actions. Our study provides novel information concerning the use of PA in cancer inhibition.

\section{Acknowledgements}

Support: The Breast Cancer Research Foundation and Hormel Foundation.

\section{References}

1. Syed DN, Afaq F and Mukhtar H: Pomegranate derived products for cancer chemoprevention. Semin Cancer Biol 17: 377-385, 2007.

2. Jurenka JS: Therapeutic applications of pomegranate (Punica granatum L.): a review. Altern Med Rev 13: 128-144, 2008.

3. Moneam NM, el Sharaky AS and Badreldin MM: Oestrogen content of pomegranate seeds. J Chromatogr 438: 438-442, 1988.

4. Belury MA: Inhibition of carcinogenesis by conjugated linoleic acid: potential mechanisms of action. J Nutr 132: 2995-2998, 2002.

5. Buell P: Changing incidence of breast cancer in JapaneseAmerican women. J Natl Cancer Inst 51: 1479-1483, 1973.

6. Dyerberg J, Bang HO and Hjorne N: Fatty acid composition of the plasma lipids in Greenland Eskimos. Am J Clin Nutr 28: 958-966, 1975.

7. Lansky EP and Newman RA: Punica granatum (pomegranate) and its potential for prevention and treatment of inflammation and cancer. J Ethnopharmacol 109: 177-206, 2007.

8. Stark AH, Crawford MA and Reifen R: Update on alpha-linolenic acid. Nutr Rev 66: 326-332, 2008.

9. Bhattacharya A, Banu J, Rahman M, Causey J and Fernandes G: Biological effects of conjugated linoleic acids in health and disease. J Nutr Biochem 17: 789-810, 2006.

10. Lansky EP, Harrison G, Froom P and Jiang WG: Pomegranate (Punica granatum) pure chemicals show possible synergistic inhibition of human PC-3 prostate cancer cell invasion across Matrigel. Invest New Drugs 23: 121-122, 2005.

11. Grossmann ME, Nkhata KJ, Mizuno NK, Ray A and Cleary MP: Effects of adiponectin on breast cancer cell growth and signaling. Br J Cancer 98: 370-379, 2008.

12. Miglietta A, Bozzo F, Bocca C, et al: Conjugated linoleic acid induces apoptosis in MDA-MB-231 breast cancer cells through ERK/MAPK signalling and mitochondrial pathway. Cancer Lett 234: 149-157, 2006.

13. Kamal-Eldin A and Appelqvist LA: The chemistry and antioxidant properties of tocopherols and tocotrienols. Lipids 31: 671-701, 1996.

14. Takai Y, Kishimoto A, Kikkawa U, Mori T and Nishizuka Y: Unsaturated diacylglycerol as a possible messenger for the activation of calcium-activated, phospholipid-dependent protein kinase system. Biochem Biophys Res Commun 91: 1218-1224, 1979.

15. Kishimoto A, Takai Y, Mori T, Kikkawa U and Nishizuka Y: Activation of calcium and phospholipid-dependent protein kinase by diacylglycerol, its possible relation to phosphatidylinositol turnover. J Biol Chem 255: 2273-2276, 1980.

16. Tappel AL: Protection against free radical lipid peroxidation reactions. Adv Exp Med Biol 97: 111-131, 1977.

17. Frankel EN: Secondary products of lipid oxidation. Chem Phys Lipids 44: 73-85, 1987

18. Gago-Dominguez M, Castelao JE, Yuan JM, Ross RK and Yu MC: Lipid peroxidation: a novel and unifying concept of the etiology of renal cell carcinoma. Cancer Causes Control 13: 287293, 2002.

19. Halliwell B: Oxidants and the central nervous system: some fundamental questions. Is oxidant damage relevant to Parkinson's disease, Alzheimer's disease, traumatic injury or stroke? Act Neurol Scan (Suppl) 126: 23-33, 1989.

20. Hu W, Feng $\mathrm{Z}$ and Eveleigh J: The major lipid peroxidation product, trans-4-hydroxy-2-nonenal, preferentially forms DNA adducts at codon 249 of human p53 gene, a unique mutational hotspot in hepatocellular carcinoma. Carcinogenesis 23: 1781$1789,2002$.

21. Sander CS, Hamm F, Elsner P and Thiele JJ: Oxidative stress in malignant melanoma and non-melanoma skin cancer. Br J Dermatol 148: 913-922, 2003. 
22. Berliner JA and Heinecke JW: The role of oxidized lipoproteins in atherogenesis. Free Radic Biol Med 20: 707-727, 1996.

23. Gago-Dominguez M, Castelao JE, Pike M, Sevanian A and Haile RW: Role of lipid peroxidation in the epidemiology and prevention of breast cancer. Cancer Epidemiol Biomarkers Prev 14: 2829-2839, 2005.

24. Gago-Dominguez M, Jiang X and Castelao JE: Lipid peroxidation, oxidative stress genes and dietary factors in breast cancer protection: a hypothesis. Breast Cancer Res 9: 201-211, 2007.

25. González MJ and Riordan NH: The paradoxical role of lipid peroxidation on carcinogenesis and tumor growth: a commentary. Medical Hypoth 46: 503-504, 1996.

26. Coursin DB, Cihla HP, Sempf J, Oberley TD and Oberley LW: An immunohistochemical analysis of antioxidant and glutathione S-transferase enzyme levels in normal and neoplastic human lung. Histol Histopathol 11: 851-860, 1996.

27. Hileman EO, Liu J, Albitar M, Keating MJ and Huang P: Intrinsic oxidative stress in cancer cells: a biochemical basis for therapeutic selectivity. Cancer Chemother Pharmacol 53: 209-219, 2004.

28. Oberley TD and Oberley LW: Antioxidant enzyme levels in cancer. Histol Histopathol 12: 525-535, 1997.

29. Cejas P, Casado E, Belda-Iniesta C, et al: Implication of oxidation stress and cell membrane lipid peroxidation in human cancer (Spain). Cancer Causes Control 15: 707-719, 2004.

30. Chandra J, Samali A and Orrenius S: Triggering and modulation of apoptosis by oxidative stress. Free Rad Biol Med 29: 323-333, 2000.
31. Ozben T: Oxidative stress and apoptosis: impact on cancer theory. J Pharmaceut Sci 96: 2181-2196, 2007.

32. Albright CD, Klem E, Shah AA and Gallagher P: Breast cancer cell-targeted oxidative stress: Enhancement of cancer cell uptake of conjugated linoleic acid, activation of p53, and inhibition of proliferation Exp Molec Pathol 79: 118-125, 2005.

33. Albright CD, Salganik RI and van Dyke T: Dietary depletion of vitamin $\mathrm{E}$ and vitamin A inhibits mammary tumor growth and metastasis in transgenic mice. J Nutr 134: 1139-1144, 2004

34. Salganik RI, Albright CD, Rodgers J, et al: Dietary antioxidant depletion: enhancement of tumor apoptosis and inhibition of brain tumor growth in transgenic mice. Carcinogenesis 21: 909-914, 2000.

35. Stoll BA: n-3 Fatty acids and lipid peroxidation in breast cancer inhibition. Br J Nutr 87: 193-198, 2002.

36. Rigas B and Sun Y: Induction of oxidative stress as a mechanism of action of chemopreventive agents against cancer. Br J Cancer 98: 1157-1160, 2008.

37. Jude S, Roger S, Martel E, et al: Dietary long-chain omega-3 fatty acids of marine origin: a comparison of their protective effects on coronary heart disease and breast cancers. Prog Biophys Mol Biol 90: 299-325, 2006.

38. Griner EM and Kazanietz MG: Protein kinase C and other diacylglycerol effectors in cancer. Nat Rev Cancer 7: 281-294, 2007.

39. Grossmann ME, Mizuno NK, Dammen ML, Schuster T, Ray A and Cleary MP: Eleostearic acid inhibits breast cancer proliferation by means of an oxidation-dependent mechanism. Cancer Prev Res 2: 879-886, 2009. 